\title{
Transmittance spectroscopy and transmitted multispectral imaging to map covered paints
}

\author{
Antonino Cosentino \\ Cultural Heritage Science Open Source, Piazza Cantarella 11, Aci Sant'Antonio, 95025, Italy \\ antoninocose@gmail.com
}

\begin{abstract}
Transmitted spectroscopy and transmitted multispectral imaging in the 400-900 $\mathrm{nm}$ range have been applied for the mapping and tentative identification of paints covered by a white preparation as in the case of a ground laid for reusing a canvas for another painting. These methods can be applied to polychrome works of art, as long as their support and new preparation are sufficiently translucent. This work presents the transmittance spectra acquired from a test board consisting of a prepared canvas with swatches of 54 pigments covered with titanium white and the multispectral images realized with transmitted light to map covered paints on a mock-up painting. It was observed that 18 out of 54 historical pigments provide characteristic transmittance spectra even underneath a titanium white preparation layer and that transmitted light multispectral imaging can map hidden paint layers.
\end{abstract}

Espectroscopia de transmissão e imagiologia multiespectral de transmissão para a visualização de pinturas subjacentes

\section{Resumo}

A espectroscopia de transmissão e a imagiologia multiespectral de transmissão no intervalo entre 400 e $900 \mathrm{~nm}$ foram usadas para a detecção e possível identificação de pinturas encobertas por uma camada branca semelhante à camada de preparação que é aplicada sobre a pintura já existente numa tela quando se pretende reutilizá-la. Estes métodos podem ser usados com obras de arte polícromas desde que o suporte e a preparação sejam suficientemente translúcidos. Este trabalho apresenta os espectros de transmissão obtidos com um painel de teste, constituído por uma tela com preparação sobre a qual foram aplicadas amostras de tintas de 54 pigmentos que foram cobertas por uma camada de branco de titânio, e as imagens multiespectrais de luz transmitida obtidas com o objectivo de mapear as pinturas dess painel. Dezoito dos 54 pigmentos históricos proporcionaram espectros de transmissão característicos, mesmo sob uma camada de preparação de branco de titânio, e as imagens multiespectrais de luz transmitida permitiram mapear as zonas pintadas.

\section{Keywords}

Multispectral imaging Pigments identification Transmittance spectroscopy Reflectance spectroscopy

\section{Palavras-chave}

Imagem multiespectral Identificação de pigmentos Espectroscopia de transmissão Espectroscopia de reflexão 


\section{Introduction}

The detection of underlying layers, such as underpainting, modifications to the original sketch (pentimenti) or hidden compositions on a reused canvas is of great importance in art conservation. The more commonly used techniques to reveal these features are X-ray radiography [1], infrared reflectography [2-3] and neutron autoradiography [4], while the mapping of hidden paint layers on canvas has also been recently tried with innovative techniques such as Terahertz imaging [5] and XRF mapping [6]. Multispectral [7-10] and hyperspectral [11-14] imaging are used for non-invasive identification and mapping of pigments in polychrome artworks and also for the detection of hidden layers when extended to the near infrared range.

This study discusses the use of transmittance spectroscopy and multispectral imaging with transmitted radiation (MSIT) for the identification of pigments and their mapping when hidden beneath another layer of paint, as in the case of a white ground preparation laid for reusing the canvas [15]. This method can be applied to polychrome works of art, as long as their support and preparation are sufficiently translucent. Support, preparation, paints, and the covering layer must be thin enough to allow visible and infrared radiation to pass through and be measured with a transmittance spectrometer.

This work illustrates the measurements acquired from a test board consisting of a prepared canvas with swatches of pigments covered with titanium white. The spectra were acquired with a miniaturized and portable spectrometer covering the VIS-NIR range. The transmitted spectrum shows the ratio between the intensity of the transmitted light and the incident light (transmittance) expressed in percentage. Similar to reflectance spectroscopy, transmittance spectra can provide useful information for the identification of pigments, since the light is absorbed depending on the chemical composition of the material tested. Reflectance spectroscopy has been used from the late 1980s [16] and there are reference spectra databases for pigments [17-18].

The main advantage of transmittance spectroscopy and MSIT with respect to other spectroscopy and imaging methods currently applied for revealing hidden paint layers is that the equipment is relatively low in cost. Transmittance spectra are acquired with the same equipment as reflectance spectroscopy: a light source, a spectrometer, a probe and one optical fiber to collect the transmitted light. Similarly, MSIT can be performed with the same equipment used for traditional (reflected radiation) multispectral imaging. Another important advantage is that the most used white pigments to make a preparation layer (lead white, zinc white, titanium white and lithopone) are very opaque when examined in reflected imaging but they become very transparent with transmitted infrared imaging [19]. The same white pigments, and in particular lead white, are opaque in X-radiography and
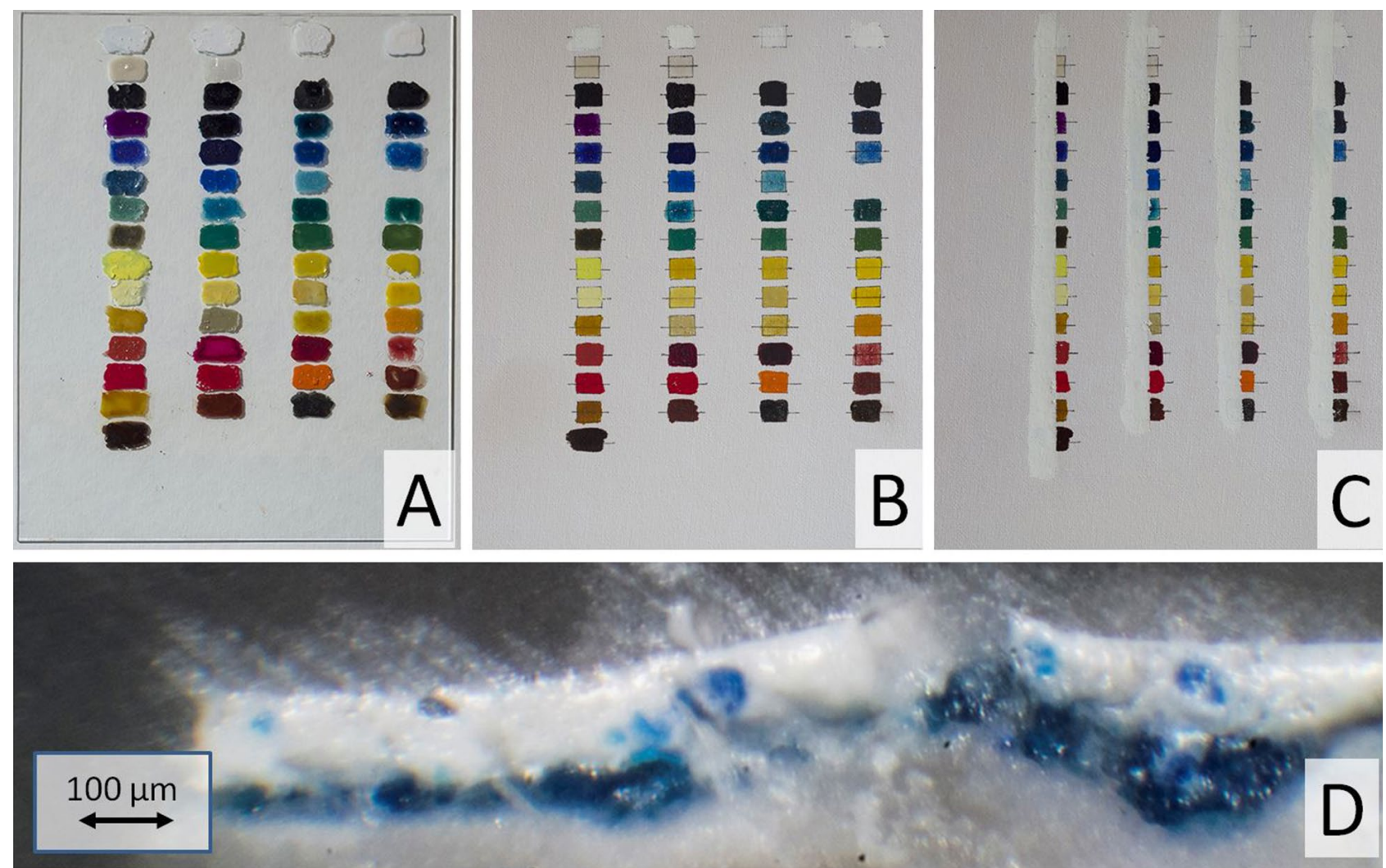

Figure 1. 54 historical pigments laid on: $a$ ) glass plate; $b$ ) test board. $c$ ) The same test board where the pigments swatches are half covered behind a titanium white paint layer. $d$ ) Cross-section of the test board: Egyptian blue covered by the titanium white preparation. 
infrared reflectography, and usually they hide the under paints. For this reason, other methods have been applied, such as Terahertz scanning [5], which is not affected by the lead-containing preparation layer. These methods are costly and require highly specialized personnel and facilities, while transmittance spectroscopy and MSIT can be implemented with comparatively much lower budgets.

\section{Methods}

\section{Samples}

This paper presents the transmittance spectra of 54 historical pigments that have been laid with gum arabic on a glass plate (Figure 1). A swatch of just gum arabic is added as a reference for the binder. The pigments were hand mulled into the gum arabic (as much as required to wet each pigment) and applied to the glass plate with a brush.

While not intended as an exhaustive list, the 54 pigments represent a selection of the most widely used ones from antiquity to the early 1950s. Table 1 lists the pigments used in this study, which are all distributed by Kremer Pigments. Information about their composition and manufacture is available directly from the Kremer website [20] by searching the specific product code.

A second test board was prepared using swatches of the same 54 pigments on a pure-cotton, mediumgrain canvas with a titanium white acrylic ground layer preparation (Ferrario, Italy). The swatches were then fixed using an acrylic resin (Maimeri \# 675) and half the surface was covered with a layer of titanium white. A test painting consisting of nine pigments laid out as geometric shapes and then covered with a single layer of titanium white was also prepared (Figure 2). Since this is a preliminary study, among all the possible white paints and grounds, only titanium white was evaluated for both the original preparation and the covering layer. Titanium white replaced lead white and it is the most diffused white pigment after 1930 .

\section{Instrumentation}

The transmission spectra were acquired with ASEQ LR1 spectrometer $(300-1000 \mathrm{~nm}, 2 \mathrm{~nm}$ resolution with $100 \mu \mathrm{m}$ slit) featuring a Toshiba TCD1304DG linear array (3648 pixels). The spectrometer was coupled with the ASEQ light source (CH-S2) and ASEQ fiber-optics probe F01_R03 consisting of seven fibers (600 $\mu \mathrm{m}$ core), six for excitation and one for collection. The multispectral imaging system is composed of a PixelTeq SpectroCam UV-VIS CCD camera and eight interferential filters manufactured by the same company (center wavelength/ bandwidth $\mathrm{nm}$ ): 860/20, 800/10, 780/20, 740/10, 717/10, $578 / 10,511 / 20,425 / 50$. This camera incorporates a highsensitivity 5 Megapixel CCD in the range 200-1000 nm and a sequential 8-band filter-wheel [21-22].
Table 1

List of pigments with the Kremer Pigments product code.

\begin{tabular}{|c|c|}
\hline Colours & Pigments \\
\hline Blacks & $\begin{array}{l}\text { Ivory black, } 12000 \\
\text { Vine black, } 47000 \\
\text { Bone black, } 47100 \\
\text { Lamp black, } 47250\end{array}$ \\
\hline Blues & $\begin{array}{l}\text { Azurite, } 10200 \\
\text { Blue bice, } 10184 \\
\text { Cobalt blue, } 45730 \\
\text { Egyptian blue, } 10060 \\
\text { Indigo, } 36005 \\
\text { Maya blue, } 36007 \\
\text { Prussian blue, } 45202 \\
\text { Smalt, } 10000 \\
\text { Ultramarine nat, } 10510 \\
\text { Phthalo blue, } 23050 \\
\text { Cobalt violet, } 45800\end{array}$ \\
\hline Browns & $\begin{array}{l}\text { Burnt Sienna, } 40430 \\
\text { Burnt umber, } 40710 \\
\text { Van Dyke brown } 41000 \\
\text { Raw Sienna, } 17050 \\
\text { Raw umber, } 40610\end{array}$ \\
\hline Greens & $\begin{array}{l}\text { Cadmium green, } 44510 \\
\text { Chrome green, } 44200 \\
\text { Cobalt green, } 44100 \\
\text { Green earth, } 11000 \\
\text { Malachite, } 10300 \\
\text { Phthalo green, } 23000 \\
\text { Verdigris, } 44450 \\
\text { Viridian, } 44250\end{array}$ \\
\hline Reds & $\begin{array}{l}\text { Alizarin, } 23600 \\
\text { Cadmium red, } 21120 \\
\text { Red lead, } 42500 \\
\text { Read ochre, } 11574 \\
\text { Vermilion, } 10610 \\
\text { Madder lake, } 372051 \\
\text { Lac dye, } 36020 \\
\text { Carmine lake, } 42100 \\
\text { Realgar, } 10800\end{array}$ \\
\hline Whites & $\begin{array}{l}\text { Lead white, } 46000 \\
\text { Zinc white, } 46300 \\
\text { Lithopone, } 46100 \\
\text { Titanium white, } 46200 \\
\text { Gypsum, } 58300 \\
\text { Chalk, } 58000\end{array}$ \\
\hline Yellows & $\begin{array}{l}\text { Cadmium yellow, } 21010 \\
\text { Cobalt yellow, 43500 } \\
\text { Lead Tin yellow I, } 10100 \\
\text { Lead Tin yellow II, } 10120 \\
\text { Massicot, } 43010 \\
\text { Naples yellow, } 10130 \\
\text { Orpiment, } 10700 \\
\text { Saffron, 36300 } \\
\text { Yellow ochre, } 40010 \\
\text { Yellow Lake reseda, } 36262 \\
\text { Gamboge, } 37050\end{array}$ \\
\hline
\end{tabular}

\section{Results and discussion}

The transmittance spectra of the 54 swatches of pigments laid on the glass plate were acquired with the ASEQ LR1 system (Figure 3). The paint itself acts as a diffuser and the light source $(\mathrm{CH}-\mathrm{S} 2)$ attached to the spectrometer was located just behind the paint, while on the other side (facing the paint) the probe collects transmitted light and delivers it to the spectrometer. Transmittance spectra were measured using the 

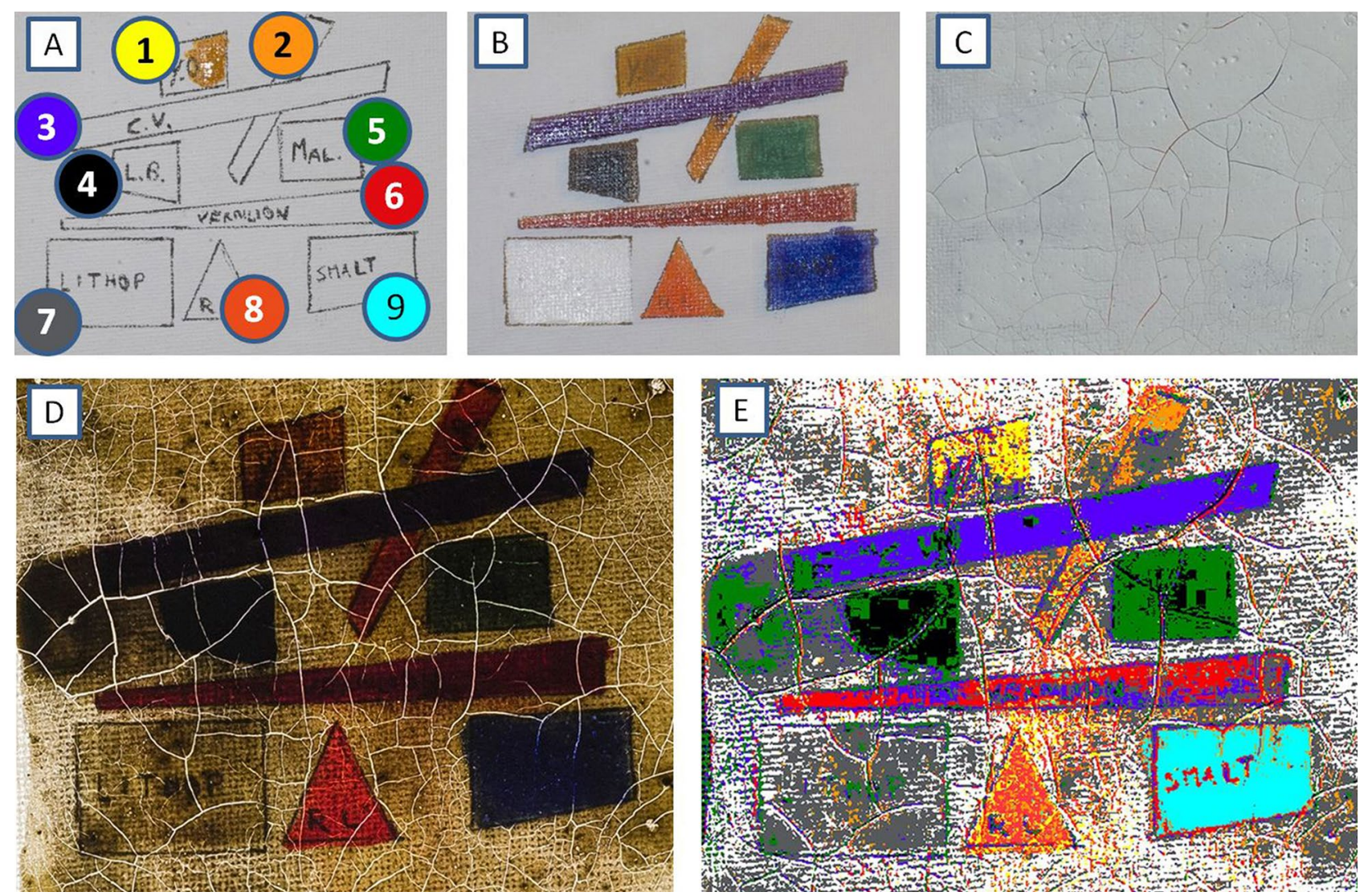

Figure 2. Test painting. a) Nine shapes were drawn on the prepared canvas. $b$ ) The shapes were painted with: yellow ochre (1), realgar (2), cobalt violet (3), lamp black (4), malachite (5), vermilion (6), lithopone (7), red lead (8) and smalt (9). c) titanium white was applied to cover the shapes. $d$ ) Transmitted light photo (lighting from the canvas side). e) Multispectral imaging transmitted segmentation of the painting (color code is as indicated in $a$ ).

following parameters: integration time $50 \mathrm{~ms}$, scans to average 10 , boxcar 15 . Reference spectrum was taken on the glass plate without any paint or binder. The spectra acquired in the range $400-900 \mathrm{~nm}$ are available for download [23]. The UV region was omitted because of the specific goal of this study, i.e. to map and identify pigments on canvas or other translucent supports through transmitted light (UV radiation is mostly absorbed by the support, and the halogen light sources, otherwise used for VIS and IR illumination, do not have sufficient UV component). Measurements into the infrared region were limited to $900 \mathrm{~nm}$ because the transmittance spectra become saturated at longer wavelengths due to the increased transmittance in the infrared from the pigment-binder mixture. Transmittance spectra feature the same absorption bands as in reflectance spectroscopy. Consequently, only a few cases are discussed. Gum arabic does not have any characteristic spectral feature. Titanium white is characterized by its sharp UV absorbance band, which extends into the blue region, while that of zinc white is much smoother. Lithopone, a mixture of barium sulfide and zinc sulfide, exhibits absorption bands in the 650$800 \mathrm{~nm}$ region due to zinc sulfide. Lead white, as well as gypsum and chalk, exhibit featureless and relatively flat spectra.
Transmittance spectra from 11 different blue pigments were measured. The transmittance spectrum of cobalt violet and smalt are characterized by weak maxima, at about $515 \mathrm{~nm}$ and $560 \mathrm{~nm}$, respectively. Prussian blue and phthalo blue have respectively only one maximum, at about $450 \mathrm{~nm}$ and $492 \mathrm{~nm}$. Maya blue and indigo have large absorption bands in the red region. Ultramarine and azurite (and blue bice, its synthetic form) are differentiated by the absorbance of the latter in the infrared. Egyptian blue exhibits two absorption bands near $800 \mathrm{~nm}$ and 630 nm while cobalt blue has just one broad band between 525 $\mathrm{nm}$ and $675 \mathrm{~nm}$.
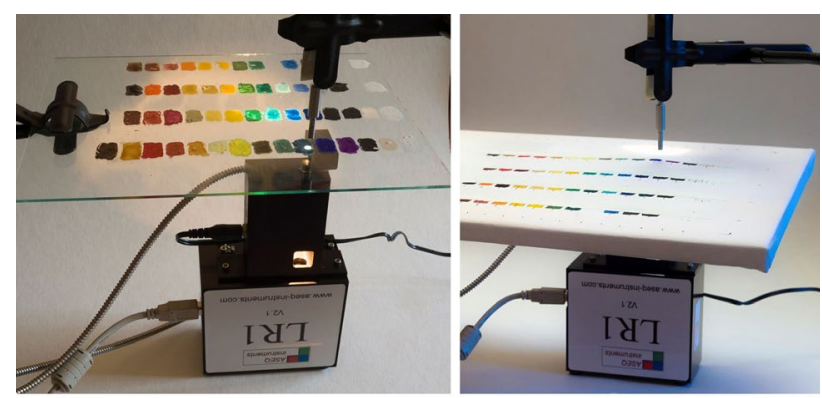

Figure 3. ASEQ LR1 spectrometer set up for transmission spectra measurement of pigments laid on the glass plate (left) and on the test board (right). 
Eight green pigments were measured. All of these but green earth share characteristic maxima in the green region. Green pigments may be differentiated between those having strong transmittance in the infrared (chrome green, cadmium green, cobalt green, viridian and phthalo green) and those that absorb infrared (malachite, verdigris and green earth).

The transmittance spectra of 12 yellow pigments were collected. Cadmium yellow exhibits a sharp inflection point at about $490 \mathrm{~nm}$. The pigment is relatively opaque and consequently the transmittance spectrum fails to reveal the absorption bands between $650 \mathrm{~nm}$ and $800 \mathrm{~nm}$, due to its zinc sulfide component, which are observed in the corresponding reflectance spectrum. Other yellow pigments have similar sharp inflection points, massicot at about $455 \mathrm{~nm}$, lead tin yellow I at about $465 \mathrm{~nm}$, yellow lake reseda at about $490 \mathrm{~nm}$, cobalt yellow at about 495 $\mathrm{nm}$, lead tin yellow II at about $510 \mathrm{~nm}$, gamboge at about $525 \mathrm{~nm}$, orpiment and saffron at about $530 \mathrm{~nm}$, Naples yellow and realgar at about $550 \mathrm{~nm}$. Yellow ochre exhibits its characteristic absorption bands in the 650-900 nm region, as seen in the corresponding reflectance spectra, due to the transitions of the ferric ion. As for the other ochers, this characterizing feature is weaker than in the corresponding reflectance spectra, probably due to the more intense scattering that the transmission measurement involves.

The transmittance spectra of eight red pigments were collected. Red lead has a sharp inflection point at about $580 \mathrm{~nm}$, vermilion and cadmium red at about $600 \mathrm{~nm}$. Carmine lake exhibits a maximum at about $545 \mathrm{~nm}$, which was not observed in the corresponding reflectance spectrum. The transmittance spectrum of lac dye has an inflection point at about $590 \mathrm{~nm}$, while the same point in the reflectance spectrum was around $715 \mathrm{~nm}$. Similarly, madder lake shifts its inflection point to about $580 \mathrm{~nm}$ from that of its reflection spectrum at $600 \mathrm{~nm}$, as well as alizarin from $610 \mathrm{~nm}$ to $710 \mathrm{~nm}$. These differences among red lakes' reflectance and transmittance spectra could be attributed to the effect of the different supports, scattering and reflection properties. Red ochre exhibits its characteristic absorption bands in the 650-900 $\mathrm{nm}$ region.

The four black pigments tested could not be differentiated by their transmittance spectra, which all exhibited a flat response across the entire range measured. Among the browns, only raw sienna and burnt sienna show, as the ochers, the absorption bands in the $650-900 \mathrm{~nm}$ region that are also characteristic of their corresponding reflectance spectra.

The pigments test board was measured with the same equipment as in Figure 3. The transmitted spectra were gathered from the canvas side (the probe facing the canvas) and from the front (facing the paint), in order to ascertain which side yielded the better signal from a pigment obscured by a preparation layer of titanium white. The best results were collected with the probe facing the paint layers. In this case, the reference spectrum was taken on a spot where the probe was facing just the original

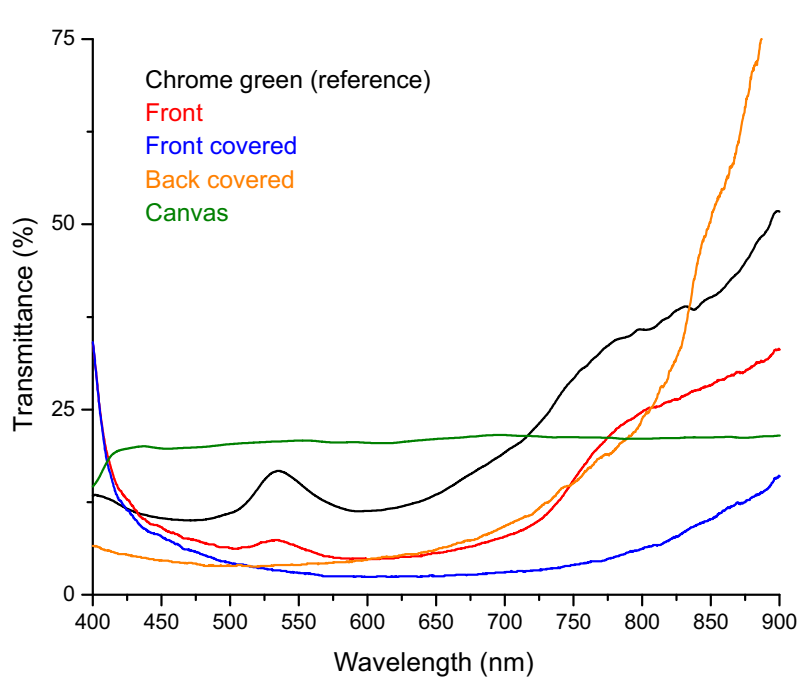

Figure 4. Transmittance spectra of chrome green on: glass plate (reference), on test board measured from the front (front) and from the front covered with titanium white (front covered), measured from the back and covered with titanium white (back covered). Transmission spectrum of the prepared canvas measured from the front (canvas).

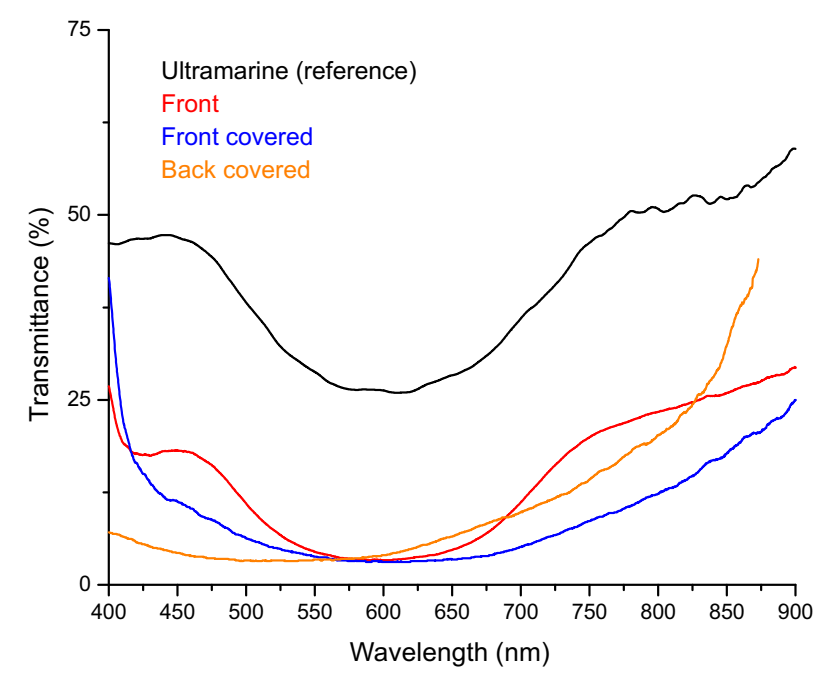

Figure 5. Transmittance spectra of ultramarine on: glass plate (reference), on test board measured from the front (front) and from the front while covered with titanium white (front covered), measured from the back and covered with titanium white (back covered).

titanium white preparation layer (without any paint and without the titanium white cover layer). Before reaching the hidden paint, the light interacts with the support and with the preparation; therefore, it is necessary to take the reference spectrum with the probe facing the exposed original preparation whenever this is possible.

The success of this method relies on the fact that the most used white pigments, such as titanium white, zinc white, lead white, gypsum and chalk, have flat transmittance spectra in the 400-900 $\mathrm{nm}$ range. Consequently, it is expected that a covering layer made with one of these white pigments will just scatter light and weaken the signal across the recorded spectrum but it 


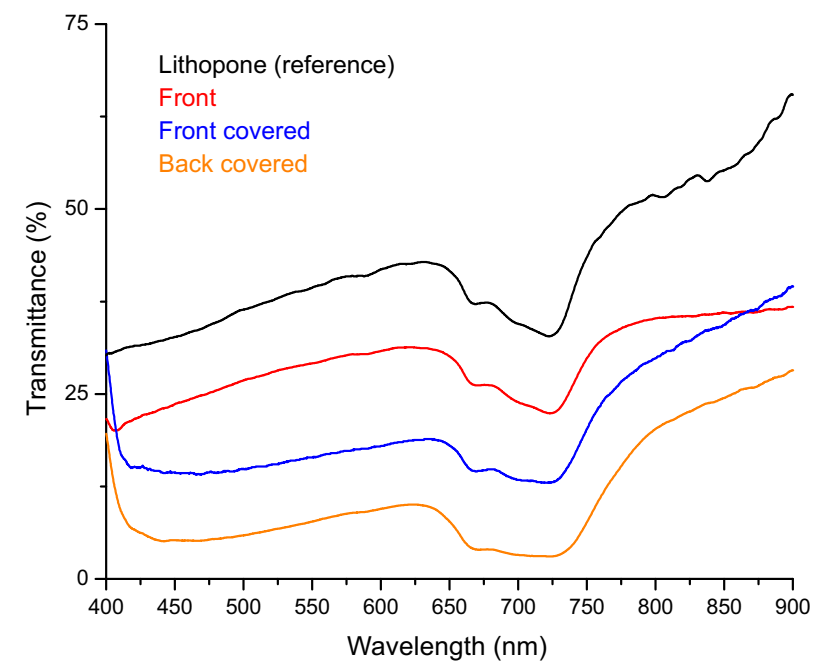

Figure 6. Transmittance spectra of lithopone on: glass plate (reference), on test board measured from the front (front) and from the front while covered with titanium white (front covered); measured from the back and covered with titanium white (back covered).

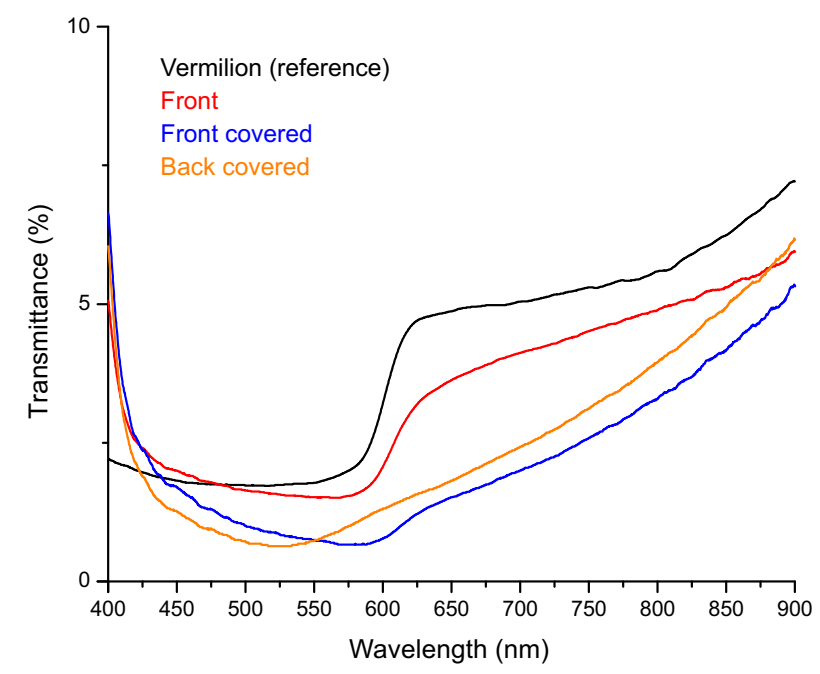

Figure 7. Transmittance spectra of vermilion on: glass plate (reference), on test board measured from the front (front) and from the front while covered with titanium white (front covered); measured from the back and covered with titanium white (back covered).

will not introduce specific features. Specifically, titanium white has a sharp absorption band in the UV region, which extends into the violet. This causes the apparent sharp transmittance increase that dominated the violet region of the spectra acquired on the prepared canvas with a titanium white preparation. On the other hand, the infrared region of these spectra also features a sharp transmittance rise due to the increased transmittance in the infrared from the pigment-binder mixture.

Figure 4 shows transmittance spectra of the chrome green paint swatch on the test board. The spectrum of the pigment on the glass plate has a very sharp maximum in the green region. Chrome green is relatively opaque and its paint layer stops almost all of the light. Consequently,

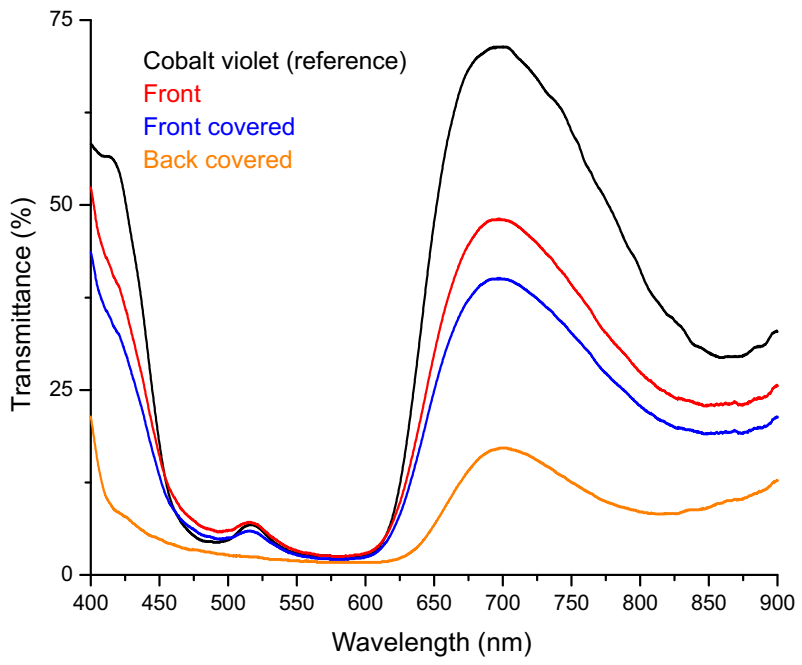

Figure 8. Transmittance spectra of cobalt violet on: glass plate (reference), on test board measured from the front (front) and from the front while covered with titanium white (front covered); measured from the back and covered with titanium white (back covered).

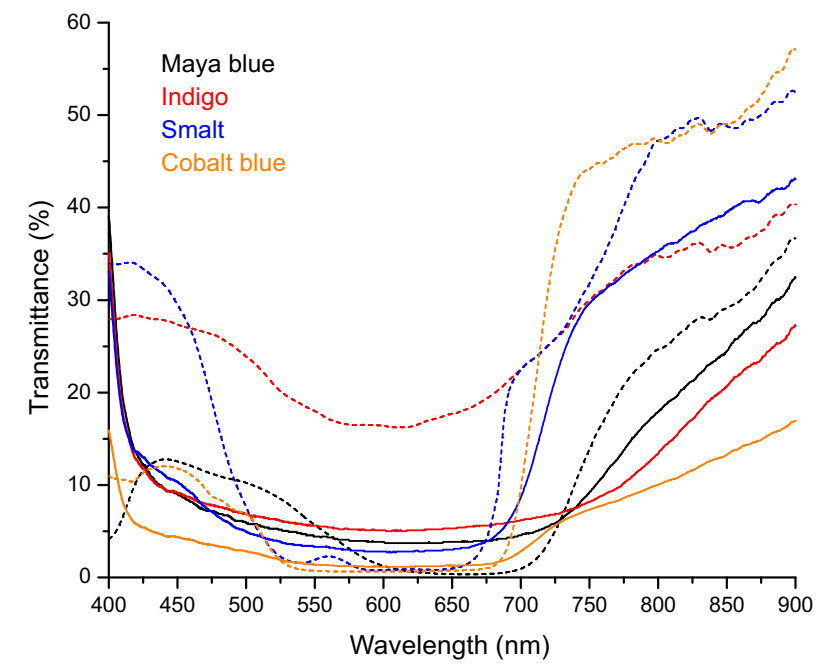

Figure 9. Transmittance spectra of blue pigments on test board covered with titanium white and corresponding reference transmittance spectra (dashed line).

the same maximum appears very weak in the spectrum taken from the front of the test board and, when the paint is covered with a layer of titanium white, the maximum cannot be detected. Similarly, the large absorption band of ultramarine between 500 and $700 \mathrm{~nm}$ is not detected when the paint is covered by titanium white in measurements taken from both the front and back of the test canvas (Figure 5).

On the other hand, lithopone is less opaque. Its transmittance spectrum exhibits characteristic features even when the paint is covered by a layer of titanium white (Figure 6). Lithopone is a mixture of barium sulfate, a good flat reflector, and zinc sulfide, which is responsible for absorption bands in the 650-800 nm 


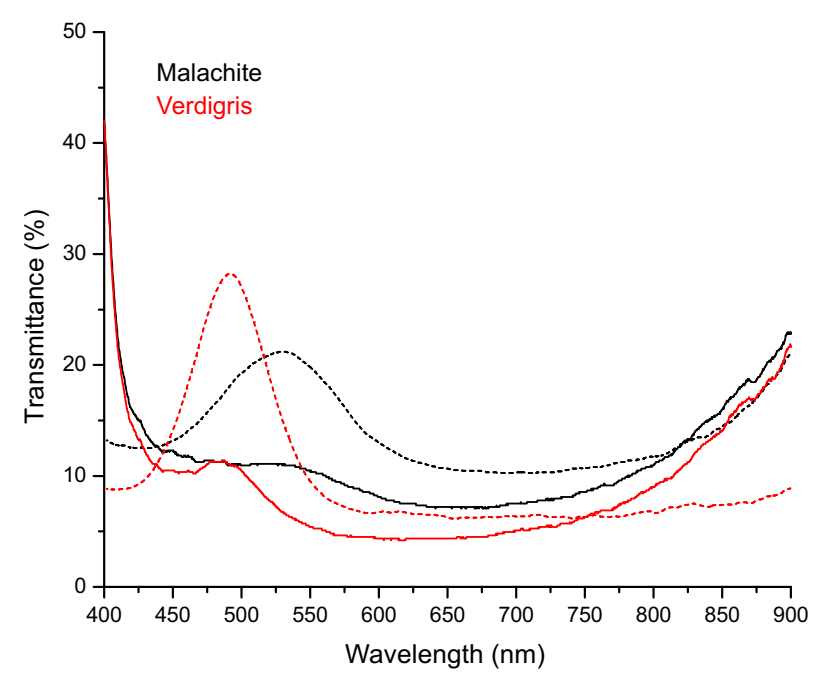

Figure 10. Transmittance spectra of green pigments which could be identified on test board covered with titanium white and corresponding reference spectra (dashed line).

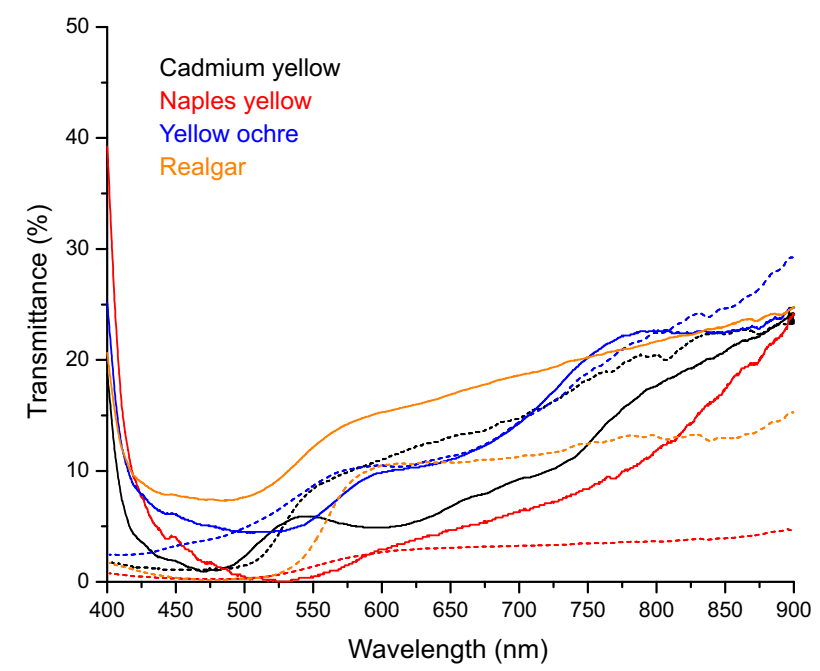

Figure 11. Transmittance spectra of yellow pigments which could be identified on test board covered with titanium white and corresponding reference spectra (dashed line).

region. Manufactured for the first time in 1874, lithopone failed to achieve wide acceptance as an artist's pigment because early formulations were not very lightfast. Later formulations of lithopone overcame the lightfastness issue but could not overcome the bad reputation and its use was limited to the priming of the canvas. One important implication of this historical fact is that now lithopone becomes useful for the non-destructive dating of artworks on canvas using transmittance spectroscopy to detect the presence of lithopone as a primer.

Vermilion, with a sharp inflection point at 600 $\mathrm{nm}$, is an example of a general class of pigments with characteristically sharp inflection points in their transmittance spectra. This unique feature is detectable, even if it is weak when the pigment is covered by a layer of titanium white (Figure 7). This signal is undetectable from the unprimed side of the test canvas.

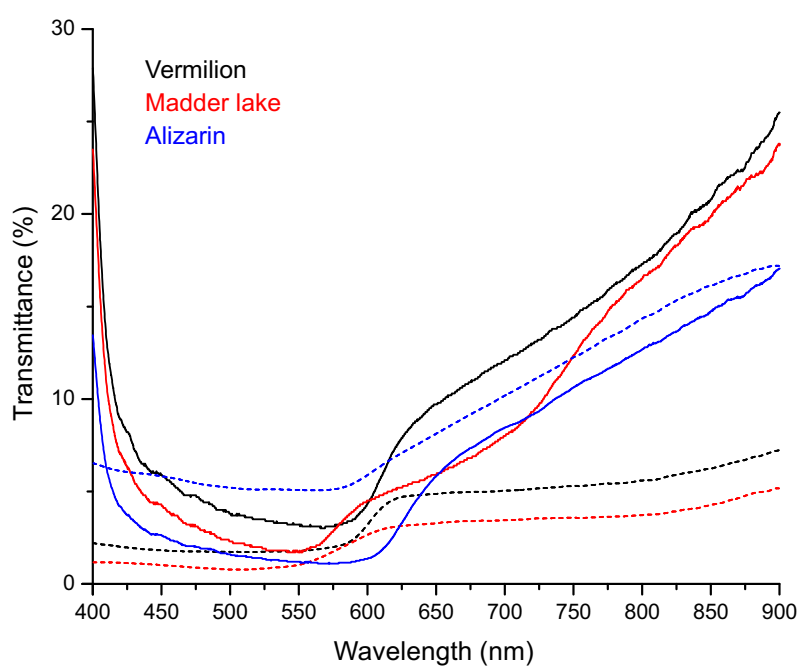

Figure 12. Transmittance spectra of reds pigments which could be identified on test board covered with titanium white and corresponding reference spectra (dashed line).

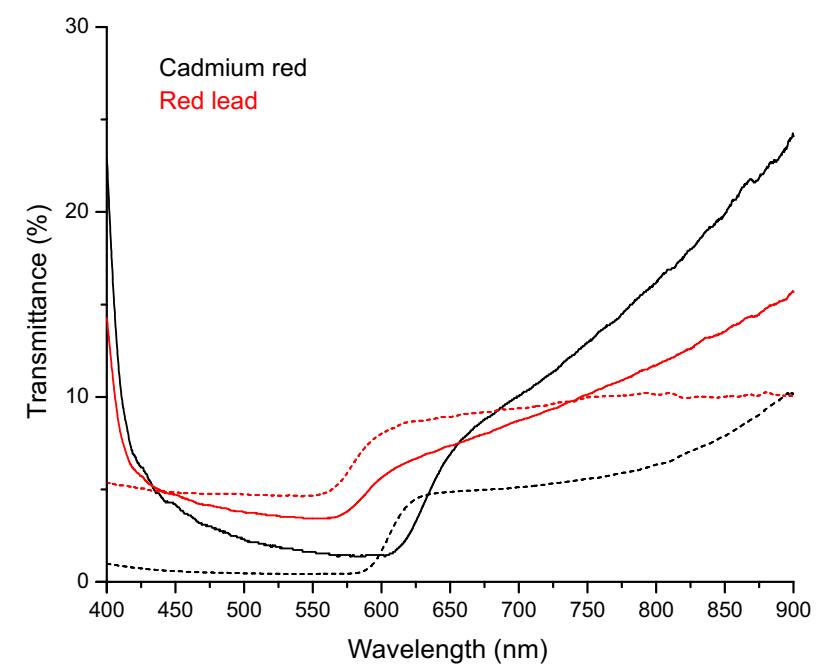

Figure 13. Transmittance spectra of reds pigments which could be identified on test board covered with titanium white and corresponding reference spectra (dashed line).

The distinguishing spectral features of cobalt violet, shown in figure 8 , are a large maximum at about $690 \mathrm{~nm}$ and a small maximum at about $515 \mathrm{~nm}$. From the front, both maxima are visible in the transmittance spectra even when the paint is covered with a layer of titanium white. In contrast, the smaller maximum is undetected in the spectrum taken from the unprimed canvas side.

Of the 54 swatches of historical pigments on the test board covered with a layer of titanium white, 18 provided spectra where all or some of their characteristic spectral features were detected:

Whites: lithopone, titanium white.

Blues: cobalt violet, Maya blue, indigo, smalt, cobalt blue (Figure 9).

Greens: malachite, verdigris (Figure 10).

Yellows: cadmium yellow, Naples yellow, yellow ochre, realgar (Figure 11). 


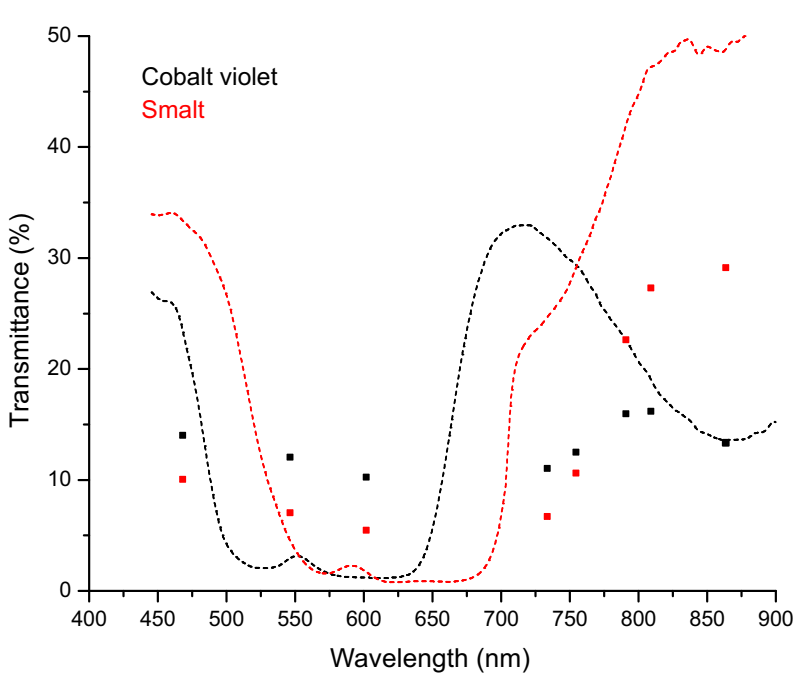

Figure 14. Test painting. Reconstructed transmittance spectra of cobalt violet and smalt covered with titanium white and corresponding transmittance reference spectra (dashed line).

Reds: vermilion, madder lake, alizarin, cadmium red, red lead (Figures 12-13).

The encouraging results from the test board and the test painting led to trying a similar experiment using the PixelTeq UV-VIS SpectroCam multispectral camera to evaluate the possibility of mapping hidden paints with multi-spectral imaging using transmitted radiation. The MSIT method is proposed only for mapping pigments using relatively large broadband filters since the amount of transmitted radiation is much less than in standard MSI. Consequently, it is unpractical to use narrow bandpass filters to reconstruct transmittance spectra.

A $400 \mathrm{~W}$ halogen lamp was set at $1.5 \mathrm{~m}$ from the canvas delivering 3000 lux on the test painting. Extreme care should be used when operating on works of art and such an intense radiation should be applied only for the time necessary for the spectral imaging acquisition. Thanks to the high sensitivity of the SpectroCam CCD the longest necessary acquisition time was just 2 seconds.

Using ImageJ [24], calibration to normalize the 8 spectral images was performed using the prepared canvas covered with the titanium white layer as in-scene reference. The images were then registered also using ImageJ. HyperCube (US Army Geospatial Center) is the imaging spectroscopy software used for the analysis of the spectral cube. This calibration method is compromised by the lack of gray in-scene references, since a valuable gray standard is not yet devised for this imaging in transmission mode. It should be composed of translucent gray references. Consequently, the reconstructed spectra are used only to map the pigments rather than actually identify them. Indeed, as shown in Figures 14 and 15, the reconstructed spectra are different from each other, even if they slightly resemble the correspondent transmittance spectra acquired with the spectrometer, since they miss a proper calibration. Nevertheless, the spectral cube turned successful in mapping all the paints under the titanium

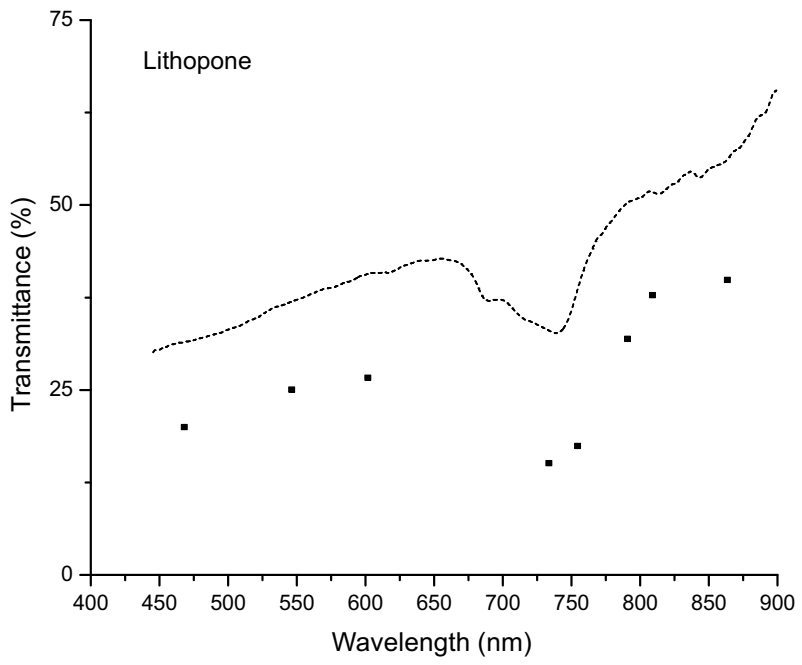

Figure 15. Test painting. Reconstructed transmittance spectra of lithopone covered with titanium white and corresponding transmittance reference spectra (dashed line).

white preparation thanks to their different reconstructed spectra (Figure 2).

\section{Conclusions}

This study explored the use of transmittance spectroscopy and multispectral imaging for the examination of polychrome artworks on translucent supports such as those that have been reused or recently covered by a new ground preparation. A collection of 54 historical pigments was tested to evaluate the feasibility of obtaining meaningful transmittance spectra from pigment samples laid out on a prepared canvas and also covered with a titanium white preparation.

The non-destructive identification of lithopone from among the other pigments by its transmittance spectrum is very important since lithopone priming represents a specific terminus post quem; its manufacture and uses since 1874 are well documented. It was observed that some pigments, especially modern ones, are too opaque to practically measure their transmittance spectra, especially when covered by a layer of titanium white.

The only differences between transmittance and reflectance spectra were noticed in lakes, while mineral pigments showed, as expected, consistency between the two different measures. The encouraging transmittance spectroscopy results led to test a multispectral imaging system with transmitted light (MSIT), which was able to map the pigments on a test painting also covered with a titanium white preparation. Further study is needed to test the pigments laid out with other binders, such as tempera and linseed oil, different translucent supports, such as cardboards for watercolor, and other white preparation paints (such as chalk, gypsum, and other white pigments). It might also prove useful to test a larger number of interferential filters for the multispectral camera in order to 
achieve a better reconstruction of the transmitted spectra and a more precise mapping. While pigment identification was successful for 18 of the 54 pigments tested, the MSIT technique allowed to map the pigments' distribution throughout a painting even if they were covered, (as in the test painting), by a titanium white preparation.

\section{Acknowledgments}

We thank PixelTeq, who kindly provided the SpectroCam UV-VIS and the filters set presented in the paper.

\section{References}

1 Gilardoni, A.; Orsini, R. A.; Taccani, S., X-Rays in Art, Gilardoni Spa, Mandello Lario (1977).

2 Cosentino, A., 'Panoramic infrared reflectography. Technical recommendations', International Journal of Conservation Science 5(1) (2014) 51-60.

3 Van Asperen de Boer, J. R. J., 'Reflectography of paintings using an infrared vidicon television system', Studies in Conservation 14(3) (1969), 96-118, doi:10.1179/ sic. 1969.010 .

4 Ainsworth, M. W.; Haverkamp-Begemann, E.; Brealey, J.; Meyers, P., Art and Autoradiography: Insights into the Genesis of Paintings by Rembrandt, Van Dyck, and Vermeer, Metropolitan Museum of Art, New York (1982).

5 Adam, A. J. L.; Planken, P. C. M.; Meloni, S.; Dik, J., 'Terahertz imaging of hidden paint layers on canvas', Optics Express 17(5) (2009) 3407-3416, doi:10.1364/oe.17.003407.

6 Alfeld, M.; De Nolf, W.; Cagno, S.; Appel, K.; Siddons, D. P.; Kuczewski, A.; Janssens, K.; Dik, J.; Trentelman, K.; Walton, M.; Sartorius, A., 'Revealing hidden paint layers in oil paintings by means of scanning macro-XRF: a mockup study based on Rembrandt's "An Old Man in Military Costume",, Journal of Analytical Atomic Spectrometry 28(1) (2013) 40-51, doi:10.1039/c2ja30119a.

7 Cosentino, A., 'Multispectral imaging and the art expert', Spectroscopy Europe 27(2) (2015) 6-9.

8 Liang, H., 'Advances in multispectral and hyperspectral imaging for archaeology and art conservation', Applied Physics A 106 (2) (2012) 309-323, doi:10.1007/s00339-0116689-1.

9 Cosentino, A., 'Panoramic, macro and micro multispectral imaging: an affordable system for mapping pigments on artworks', Journal of Conservation and Museum Studies $\mathbf{1 3}(1)$ (2015) 1-17.

10 Raju, S.; Hardeberg, J. Y., 'Multispectral imaging using LED illumination and an RGB camera', in Color and Imaging Conference, 21st Color and Imaging Conference Final Program and Proceedings, Society for Imaging Science and Technology (2013), 8-13.

11 Fischer, C.; Kakoulli, L., 'Multispectral and hyperspectral imaging technologies in conservation: current research and potential applications', Reviews in Conservation 7 (2006) 3-16, doi:10.1179/sic.2006.51.supplement-1.3.
12 Delaney, J. K.; Zeibel, J. G.; Thoury, M.; Littleton R.; Palmer, M.; Morales, K.M.; René de la Rie, E.; Hoenigswald, A., 'Visible and infrared imaging spectroscopy of Picasso's Harlequin Musician: mapping and identification of artist materials in situ', Applied Spectroscopy 64(6) (2010) 584594, doi:10.1366/000370210791414443.

13 Jackall, Y.; Delaney, J. K.; Swicklik, M., 'Portrait of a woman with a book': a 'newly discovered fantasy figure' by Fragonard at the National Gallery of Art, Washington', Burlington Magazine 157 (2015) 248-254.

14 Kubik, M., 'Hyperspectral imaging: a new technique for the non-invasive study of artworks', in Physical Techniques in the Study of Art, Archaeology and Cultural Heritage, vol. 2, ed. D. Creagh and D. Bradley, Elsevier, Amsterdam (2007) 199-259, doi:10.1016/S1871-1731(07)80007-8.

15 Dik, J.; Janssens, K.; Van Der Snickt, G.; van der Loeff, L.; Rickers, K.; Cotte, M., 'Visualization of a lost painting by vincent van gogh using synchrotron radiation based X-ray fluorescence elemental mapping', Analytical Chemistry 80(16) (2008) 6436-6442, doi:10.1021/ac800965g.

16 Bacci, M.; Cappellini V.; Carla, R., 'Diffuse reflectance spectroscopy: an application to the analysis of art works', Journal of Photochemistry and Photobiology. B: Biology 1(1) (1987) 132-133, doi:10.1016/1011-1344(87)80016-7.

17 Cosentino, A., 'FORS spectral database of historical pigments in different binders', e-conservation Journal 2 (2014) 57-68, doi:10.18236/econs2.201410.

18 'Fiber Optics Reflectance Spectra (FORS) of Pictorial Materials in the 270-1700 nm range', http://fors.ifac.cnr.it (accessed 2016-05-09).

19 Cosentino, A. 'Infrared Technical Photography for Art Examination', e-Preservation Science 13 (2016) 1-6, http://www.morana-rtd.com/e-preservationscience/2016/ ePS_2016_a1_Cosentino.pdf (accessed 2016-05-09).

20 Kremer Pigments Inc., http://kremerpigments.com (accessed 2016-05-09).

21 Cosentino, A., 'Multispectral imaging of pigments with a digital camera and 12 interferential filters', e-Preservation Science 12 (2015) 1-7, http://www.morana-rtd.com/epreservationscience/2015/ePS_2015_a1_Cosentino.pdf (accessed 2016-05-09).

22 Cosentino, A., 'Multispectral imaging system using 12 interference filters for mapping pigments', Conservar Património 21 (2015) 25-38, doi:10.14568/cp2015005.

23 http://chsopensource.org/download/7948/ (accessed 201605-09).

24 Rasband, W. S., 'ImageJ', U. S. National Institutes of Health, http://imagej.nih.gov/ij/ (accessed 2016-05-09).

Received: 2015-12-07

Accepted: 2016-04-29

Online: 2016-05-24

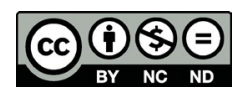

This work is licensed under the Creative Commons Attribution-NonCommercial-NoDerivatives 4.0 International License. To view a copy of this license, visit http://creativecommons.org/licenses/by-nc-nd/4.0/deed.en. 